\title{
Stories from Students in Their First Semester of Distance Learning
}

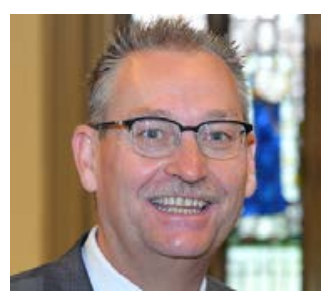

Mark Brown, Helen Hughes, Mike Keppell, Natasha Hard and Liz Smith

Dublin City University, University of Bristol, University of Southern Queensland \& Charles Sturt University

\begin{abstract}
Online and distance learning is becoming increasingly common. Some would say it has quickly become the preferred or 'new normal' mode of study throughout the world. However, surprisingly little is known about what actually happens to first year distance students once they have enrolled in tertiary institutions; what motivates them and how they actually experience the transition to formal study by distance. This gap in the literature presents a challenge for distance education providers who, worldwide, are coming under increasing scrutiny in light of poor retention, progression, and completion rates. Against this backdrop, the purpose of the current study was to gather insights and seek a deeper understanding from first-time distance learners about the nature of their experiences. The study involved a mixed method approach over three phases. This paper focuses on the third phase, which was the major component of the study. The lived experiences of 20 first-time distance learners were gathered, in their own words, using weekly video diaries for data collection. Over 22 hours of video data was transcribed and thematically analysed, from which five themes have been reported. The discussion reflects on the ways that video diaries have provided a unique insight around the complexities of distance learning - as distinct from campus-based learning. The paper concludes that the new digital learning environment made possible by the Internet offers a number of exciting possibilities for distance learners; however, more needs to be done by institutions to change the lone wolf' preconception of distance education and to avoid the 'goulash approach' to supporting distance learners. The lives of first-time distance learners are not black and white; they are complex shades of grey and this need to be taken in to account when designing appropriate learning experiences and supports to ensure student success.
\end{abstract}




\section{Introduction}

Online learning is the fastest growing sector of university-level education (Tennant, McMullen \& Kaczynski, 2009). In the United States a recent annual survey of online learning claims the number of students taking at least one online course has surpassed 6.7 million (Allen \& Seaman, 2013). Based on these figures, Allen and Seaman (2013) estimate that $32 \%$ of higher education students in the United States now take at least one course online. In New Zealand, around $26 \%$ of students at the tertiary level-that is, post-secondary-study by distance education (Ministry of Education, 2010). In 2010, Ministry of Education statistics show that universities account for $25 \%$ of total Equivalent Full-time Students (EFTS) studying by distance with $16 \%$ of undergraduate degrees being undertaken by distance learners. In Australia, Nunan (2005) estimated that 15\% of university students have studied by distance education each year in the past decade, although more recent figures suggest the proportion could be as high as 19\% (DEEWR, 2010).

Arguably, digitally mediated distance education has become the most significant change to the process of teaching and learning of the last decade (Simonson, Schlosser \& Orellana, 2011). In theory, the digital revolution has the potential to transform the 'iron triangle' of distance education to achieve wider access, higher quality, and lower cost all at the same time (Daniel, 2011). In the United Kingdom, a recent Online Learning Task Force (2011) agreed that online learning provides real opportunities for institutions to develop responsive, engaging, and interactive provision which, if offered at scale, can deliver quality and cost-effectiveness and meet growing student demands for flexible learning.

However, when thinking about maximizing online learning, institutions must consider the differences between campus-based and distance students. The annual Australian league table' of undergraduate attrition rates reveals that distance education providers struggle with retention more than traditional campus-based providers (The Australian, 2011). For example, campusbased Melbourne University had the lowest attrition rate of $6.21 \%$ while the University of New England (as an example of an institution that offers education by distance) recorded an attrition rate of 25.0\%. In 2009, the Higher Education Funding Council for England published data relating to the retention of part-time students, 6,490 of whom were campus-based while 10,025 were distance students studying via the Open University. Data revealed that $39 \%$ of campusbased part-time first degree entrants in 1996-97 had been awarded their degree within 11 years; compared to $22 \%$ at the Open University. Notes relating to this data reveal that the Open University estimated half of the 1996-97 cohort were only aiming for undergraduate credits and not, in fact, an entire first degree. Motivation is one of the many differences between distance and campus-based students that has an impact on retention rates and needs to be considered by institutions exploring online learning.

In terms of interpreting league tables, Zepke and Leach (2010) have criticized governments for often overlooking the 'soft factors' that affect students; especially distance learners. According to Kember (cited in Tyler-Smith, 2006) family circumstances, including the number and age of 
dependents, housing conditions, and the pressures of responsibilities such as earning an income to support the family, can all have a significant impact on a distance learner's decision to continue or dropout from their program of study.

Poskitt, Rees and Suddaby (2011) analysed data relating to distance students in New Zealand taken from the Australian University Survey of Student Engagement (AUSSE). In terms of 'soft factors', the AUSSE study found $61 \%$ of New Zealand's distance learners spending at least one hour per week caring for dependents, compared to 37\% of campus-based students. Also, distance students reported an average commitment of 17.6 hours per week to paid employment, in contrast to 12.9 hours per week by campus-based students. In a similar vein, Krause Hartley, J ames, and McInnis (2005) found that first year students who committed to more than 12.5 hours employment per week tended to be more likely to consider dropping out. In another study Adams, Banks, Davis and Dickson (2010) claim that over 16 hours of paid work per week can be linked to disengagement. The key point is that distance learners are likely to study under conditions that are far less common among first year campus-based undergraduates. As Poskitt, Rees and Suddaby (2011) observe:

Because of the very different learning environment extramural [distance] students are exposed to, and the differences in extramural students' demographics, backgrounds and commitments to work and family, it could be argued that external students have a very different student experience, and engage with their study differently (p.70).

In terms of supporting students, there is a dearth of literature around what actually happens to first-year distance students once they have enrolled in universities; what motivates them and how they experience learning from a distance (AUSSE, 2010; Basit \& Tomlinson, 2012). The first year learning experience is very important from a retention and engagement perspective. In Australia and New Zealand, more first-year students withdraw from study than returning students (J ames, Krause \& Jennings, 2009; Kift, 2009). Albeit from an institutional perspective of student engagement, it is claimed to be the time when the patterns of interaction are set (Pittaway \& Moss, 2006) and therefore the provision of appropriate supports and interventions in the first year of study have been found to have a positive and sustainable effect on campus-based student success (Kift, 2009). However, in the distance environment, Simpson (2003) argues that the services and interventions known to successfully support the engagement of distance learners are often applied in a seemingly 'ad hoc' manner. Simpson (2009) describes this problem as a 'goulash approach' to promoting distance learner retention.

Against this backdrop, the current study set out to address the dearth of literature around what actually happens to first-year distance learners once they have enrolled at the university-level and thereby gather stories in their own words from students in the first semester of distance learning. The research objective for this study was to contribute to the enhancement of learning support services and resources available for first-time distance learners. More specifically the intention was: 
- $\quad$ To develop a conceptual framework for identifying the most effective use of various intervention tools, supports and resources at early stages of the study lifecycle;

- $\quad$ To investigate the experiences of being a first-time distance learner from a student's perspective 'in their own words'; and

- To produce a set of overarching principles to help institutions enhance distance learner engagement and success.

\section{Methodology}

The research adopted a mixed methodology across three phases. The first phase involved a stocktake of current distance learner support services in two major distance education providers: Charles Sturt University, Australia and Massey University, New Zealand. Phase two involved a quantitative survey of a sample of first-time distance students. The focus of the current paper is the third phase, which had a strong phenomenological dimension where the experiences of a purposive sample of first-time distance learners at one university were recorded from their own point of view using video diaries for data collection. Approval to conduct phases two and three of the project was granted by the lead University's Human Ethics Committee.

In 2011, at the beginning of Semester Two, 750 potential participants enrolled for the first time in distance education. It needs to be noted that this figure is much lower than for Semester One and at the time of the study the University did not provide the same level of support for students starting mid-way through the year. In total, 144 volunteered to participate; from which 20 students were purposefully selected to broadly represent the demographic and geographic diversity of first-time distance learners. The profile of diversity was informed by a demographic analysis of the University's distance students during the 2010 academic year. Selection criteria included: age, gender, ethnicity, geographic location, subject of study, level of study, entry qualification, along with prior or current experience of tertiary study on-campus.

Using Sony bloggie ${ }^{\mathrm{TM}}$ cameras, video reflections were gathered using a diary technique adapted from previous studies. Riddle and Arnold (2007) used the "Day Experience Method" to investigate everyday life situations. They required participants to record written answers to specific questions sent at irregular intervals (between 30 and 90 minutes) between 8:00am and 10:00pm on three separate days. In contrast, Cashmore, Green and Scott (2010) adopted a freeform approach to video diaries in a longitudinal study with undergraduate students at the University of Leicester.

The present study adopted an approach that struck a balance between a structured technique and free-form approach (Brown, Hughes \& Delaney, 2015). The initial expectation was for five minutes-worth of video footage per week; although this expectation changed overtime given that the greater issue was not one of duration but "forthcomingness" and "insightfulness" of information. A "reflective prompt" protocol was designed to encourage "free-flow" reflections from participants whilst providing "fish-hooks" to elicit targeted categories of information in a lightly structured manner. This "fish-hook" technique meant each video reflection was unique to 
the participant. Within 48 hours of receiving a participant's video file, the Project Manager would respond via email with a fresh set of reflective prompts.

Rich data was collected from all participants over the first half of the Semester. During semesterbreak, eight participants chose to conclude, while 12 chose to continue until the end of semester. Although continuation of the video diaries beyond the initial six weeks was not part of the original plan as the focus was on the first few weeks, the research team was mindful of any sense in which the students felt abandoned on conclusion of the study.

The data was thematically analysed using Braun and Clarke's (2003) six-step process: (1) Familiarization; (2) Generating initial codes; (3) Searching for themes; (4) Reviewing themes; (5) Defining and naming themes; and (6) Reporting the content of themes. A theme captures something important about the data in relation to the research question, and represents some level of patterned response or meaning within the data set (Braun \& Clarke, 2003). By following a phenomenological inductive (bottom-up) approach, the student voice was retained at the forefront of the analysis. In other words, the researchers attempted to ensure the experiences, meanings, and lived reality of participants' were described as fully as possible to retain a sense of context.

\section{Results}

Twenty, first-time distance learners participated in the research: Andy, Beth, Chris, Deborah, Emma, Fiona, Geraldine, Hannah, Ian, J ack, Kane, Libby, Maggie, Nathan, Olivia, Penny, Rachel, Susan, and Tom. All names are pseudonyms. Table 1 presents a summary of the sample:

Table 1

Summary of the participant sample

$\begin{array}{ll}\text { Gender } & \text { Male (7), Female (13) } \\ \text { Age } & \text { Under 25 (4), 25-29 (4), 30-39 (6), 40-49 (4), 50-59 (2) } \\ \text { Ethnicity } & \text { Pakeha (11), Māori and/or Pasifika (8), Israeli (1) } \\ \text { Location } & \text { Campus town (11), Remote from campus (7), Overseas (2) } \\ \text { Mode } & \text { Distance only (17), Mixed mode (3) } \\ \text { Total courses } & \text { Undergraduate (18), Postgraduate (2) } \\ \text { Discipline } & \text { Business (8), Humanities (6), Education (3), Sciences (3) } \\ \text { Education } & \text { High school (8), Diploma (2), Degree papers (5), Degree (5) } \\ \text { Employment } & \text { Full time (11), Part time (4), None (3), Full time mother (2) } \\ \text { Dependents } & \text { None (11), One (1), Two or three (5), Four or more (3) }\end{array}$


Twenty-two hours of video diaries were aggregated over the course of the study. Five themes arose from the process of thematic analysis: (1) Motivating factors; (2) Inhibiting factors; (3) Importance of support; (4) Study approaches; and (5) Retrospective thoughts.

\section{Motivating Factors}

Participants were commonly motivated to invest time and money in study by the prospect of career progression. Some sought professional development within their current field, while others hoped to broaden their career prospects beyond their current vocation. Some had a specific career in mind while others had not yet committed to a specific career but were nonetheless motivated to study by the desire to raise their employment prospects. Most participants whose study choices were well aligned with clear career goals were well motivated. In the face of numerous challenges, Libby and J ack reflected on their career goals and how their aspirations were a great source of motivation. Some participants associated the attainment of a degree with moving on from past experiences towards a brighter future for themselves personally and their families. This group reflected on their lack of commitment to high school education with some regret; while others had performed well at high school but not subsequently enjoyed the privilege of higher education. Particularly prominent among female participants in this group was the association between further education and a sense of self-worth. For example, Hannah reported:

I just want to achieve something really good for me inside instead of just being a mum and sitting at home waiting for my husband.

\section{Inhibiting Factors}

Employment. Not surprisingly many of the participants were studying while in some form of employment or responsible for the care of dependents. For some, juggling study with fulltime work proved incredibly taxing. Within the first few weeks of semester, most participants began to report feelings of being torn between the pressure of work and study. Working more than 50 hours each week, Geraldine withdrew from one of her courses while J ack made the point:

My mind is not as functional at night when coming from work; [work] takes it out of me mentally.

Dependent children. Almost half the participants lived with dependent children, which seemed to affect men and women differently. Those who were fathers claimed to be active parents but on their own admission enjoyed supportive partners who assumed primary responsibility for childcare. In subtle contrast, mothers seemed to perceive themselves as the primary child caregiver; with that role not as apparent among their partners. Penny, who was juggling one course with part-time self-employment and six dependent children, described the kind of conflict that touched many of the mothers at some point: 
I have also had thoughts that this is not the right time to study because I can't get my children around giving me the time to study; my family is not on the same page as me.

Partners. The influence of partners was complex. Most described their partners as supportive and some even engaged in scholarly discussion and offered assistance with academic tasks. Even though some partners were supportive in principle, reports suggested that sometimes they struggled to get used to the change in dynamic at home. For example, Maggie shared some frustration when her husband suggested tidying the house on a night that she had allocated to study. Susan and Fiona experienced relationship troubles during the course of semester and these episodes seriously impacted their emotional capacity for study:

Unfortunately I'm going through a relationship break-up, which involves changing everything in my life so university study is far, far away in my mind.

Health and wellbeing. Almost all participants experienced unforeseen health issues over the course of semester. Some reported feelings of tiredness and exhaustion, while others were stalled by more serious winter viruses; as well as longer-term health concerns such as allergies and depression. Libby and Kane reported that their children had been hospitalized, while Libby and Beth reflected on their involvement with family who were losing their battle to live. In Rachel's case, health complications led her to withdraw in the second week. She reported:

My surgery has taken a bigger toll on me than I thought, and I am now looking at further surgery before the end of the semester.

Home environment. One quarter of participants were distracted by moving house during the course of semester which, for most, was an unforeseen circumstance. Those who shared their homes with other students found this constructive whereas those with professional flatmates tended to find them a distraction, especially when a dedicated study space was not available. Susan reflected upon how much living in a, not only distracting but a hostile environment, had impacted negatively upon her resolve to study:

The move to the new flat has been extremely positive and it means that I've enjoyed knuckling down and getting study done whereas, if it had been my old flat, I wouldn't have wanted to.

Leisure pursuits. Many participants struggled to find a healthy balance between study and leisure time. Jack was distracted by his nightly gym routine until he found it was unmanageable alongside full-time employment and four courses. Deborah and Fiona were distracted by their social calendars. Other participants who may have otherwise dedicated a couple of hours to study in the evenings found themselves engrossed in the Rugby World Cup 2011, which was taking place at the time of data collection. This was particularly the case for Kane: 
I have picked up my books once and put them down to turn on the rugby and I knew this would happen but I was hoping that I would not fall victim to it; unfortunately things have not worked out too well

Digital literacy. Most participants were reasonably comfortable using the online learning environment known as Stream following an initial orientation period. However, a few participants were limited by access and ability to use digital technology; while others - from across several generations - were limited by relatively low levels of digital learning fluency, that is, not necessarily perceiving the digital environment as an important place for learning. Two participants, both older than 45 , consistently felt overwhelmed by digital technology as Ursula described:

I'm having trouble. Go in to Stream, 'blaaa' too much information. Then in to Pairwise. There's all this technology, all these sites and I'm not really too sure what I'm supposed to be doing in any of them. It's like overload.

Socioeconomic factors. Very little was reported in relation to socioeconomic limitations; and nor was this the focus of the research. However, a couple of participants reflected upon financial difficulties and how this distracted from study. Olivia reported:

I've had a lot of money problems this week. That has to be my biggest stress of the week. It really upsets me and distracts me completely. It makes studying really hard when you're worrying about how to buy the groceries.

Prior experience. Two-thirds of participants had prior tertiary-level experience. However, reflections suggested that their study skills had been heavily conditioned to an internal learning environment and that distance study techniques were not necessarily intuitive. More than one third of participants were returning to study for the first time since high school after an interval of more than a decade. From within this group, some struggled to find effective study techniques to meet the demand of university-level study. For example, Libby described:

I've done a lot of research on how to do an assignment but it doesn't seem to make a lot of sense to me.

\section{Making Use of Support}

Avid support seekers. This group typically sought support from within the online learning environment. They engaged early with the distance library website and the learning support website provided by the University's Centre for Teaching and Learning. They regularly contributed to online discussions forums with fellow students via Stream and/or Facebook groups, while Beth generated discussion and debate through reflections on her personal blog. Avid support seekers were particularly interested in contact with lecturers for the purpose of discussion, reassurance and feedback. To this end, they typically attended contact courses, which they described as the highlight of their distance learning experience. Attending a university campus helped them integrate with other students and maximise university support services. 
Penny, who had a strong preference for face-to-face interaction, initiated a campus-based study group. Having moved house to live closer to campus, Susan reported spending six hours each day in the university library. Olivia particularly enjoyed campus-based meetings with Learning Consultants:

I've just been thinking because I've done two degrees, I think I'm so proficient, why would I need to learn any other techniques. Thinking like that has stopped me going to learning centre. So I'm glad I've conquered that one. Old dogs can learn new tricks.

Self-sufficient learners. In contrast, around three-quarters of participants adopted more of a lone wolf' approach to study. They did not frequent campus - including those who lived in a campus town - and they did not attend their contact courses. Some did not attend contact courses due to family circumstances, while others attributed little value to the opportunity. Kane was content with contacting his lecturer exclusively via email, while others preferred to make no contact whatsoever. Emma resolved to schedule a meeting with her lecturer but later admitted that the meeting never eventuated due to her own laziness. Similarly, the selfsufficient initiated barely any interaction with fellow students. They had mixed views about the benefits of discussion forums on Stream and the role that these played in their learning experience. Many preferred only to read and observe the Moodle discussion fora. It emerged that, for some, good intentions to contribute did not manifest because they feared their contributions would leave them exposed. Nathan offered the explanation that social confidence was a major factor, saying:

Stream is available but people's base fears of putting something out there and being wrong... it's very different to leaning over to a peer and checking for immediate reinforcement.

\section{Study Approaches}

Active-strategic approach. An active-strategic approach was distinct among taskoriented participants who were committed to being thorough. Confidently, most believed that they were capable of achieving A-grades. Most indicated that they would not be doing themselves justice if they settled for C-grades; even though "C's pass degrees." To this end, they demonstrated a reasonable level of academic capital by giving careful consideration to assignment questions long in advance of the assignment deadline, which enabled them to take a steady and reflective approach to the reading and writing process. They allowed enough time for their work to be reviewed by partners, friends, colleagues, and even the University assignment pre-reading service. In terms of their time management, they established a sustainable study routine that accounted for predictable as well as unpredictable distractions and, in the face of adversity, they demonstrated resilience with conviction, as Ian described:

Obviously it wasn't a masterpiece so I learn from it for the future but I'm not withdrawing my plan [to achieve A grades]; I still think it was good what I did. 
Active-deep approach. An active-deep approach describes participants who truly embraced the learning experience, not so much as a task but for personal self-fulfilment. A deep approach seemed to be reported when there were high levels of interest in the topic being studied. Interest alone did not guarantee success but it certainly arose as the starting point for moments of deep learning. Nathan was a good example of someone whose new knowledge was relevant to his current employment, which consequently enhanced his everyday experience at work. For Hannah, her future career was undecided but nevertheless, new knowledge and the applied nature of distance study enriched her appreciation of everyday contexts. However, only a few participants reported sourcing evidence above and beyond course expectations, as Olivia described:

I guess I've been going deeper when [I am told] I don't need to; but I can't retain information if I don't understand it and connect it in a wider context.

Passive-surface approach. A third approach can be described as a passive-surface approach. The data would suggest that $75 \%$ of participants struggled with passive feelings for prolonged periods of time. The knowledge that "C's pass degrees" was comforting in these times, as Fiona described:

I found about 10:00pm that night that it [the assignment] was only worth $6 \%$ so I wasn't enthused for it, which was a bad attitude but that's what happened.

The reasons behind participant's passive approaches were complex but frequently perceived by participants as beyond their own control. A sense of dependency (e.g., waiting for someone else to solve their problems) was particularly common (although not universal) among participants with little or no prior tertiary experience and/or those returning to study following a prolonged absence. These participants invariably reflected on a genuine desire to engage strategically - if not deeply - with their studies but appeared to be inhibited by relatively traditional conceptions of study. In other words, these students were somewhat "syllabus-bound" (Anderson, Lee, Simpson \& Stein, 2011) and unsure how to source support in the university academic environment. This lack of academic capital and sense of dependency was frequently compounded by procrastination. For example, Jack was limited by academic confusion and full-time employment but, upon taking annual leave, he confessed that he had "become lazy" and that his "study routine was terrible." Kane confessed to procrastinating during the course of his weekly diary but simultaneously cited winter sickness as justification for missing a deadline. Deborah was another who procrastinated from the outset:

It's Sunday. I went to buy printer paper. I've been disorganised. I forgot semester started on Monday... I'd like to get more organised and set aside a set time every day rather than procrastinate... This afternoon was good. I wrote a to-do list.

\section{Retrospective Thoughts}

Overall, I excelled. Around one quarter of participants summarised their semester as predominantly positive having enrolled in, more-or-less, the right number of courses to suit their 
lifestyle. This group, who also tended to report an active approach to learning, were rewarded with strong grades from the outset and believed that they had sustained their level of performance until the end of semester. Importantly, they never reported considering withdrawal. Looking to the future, they unanimously agreed that distance education was right for them. As an example, Olivia concluded:

I finished my paper [course] and I was quite elated. I feel like I've got a 60 or possibly a $70 \%$. I actually feel a lot more confident taking distance papers now.

Overall, I survived. Around one quarter of participants summarised their semester as a challenge during which they had struggled to keep their heads above water. Nevertheless, they had persevered, never doubting their long-term commitment to distance study. Although this group believed they had passed the majority of their courses, a few participants who were already disadvantaged by poor assignment grades feared that their exam performance would not earn them a pass mark. Most concluded that their first semester studying by distance was thus somewhat exploratory with several resolving to study fewer courses per semester. As an example, J ack reported:

The problem is finding the time to study while my brain is fresh and not tired so I am looking to go back next year and just do one paper in the first semester.

Overall, I struggled. As many as half the participants admitted feeling consistently overwhelmed as they struggled to balance study with lifestyle limitations. This group frequently contemplated withdrawal, particularly after the mid-semester point, and some did actually withdraw from a course. Out of this group those distance learners who participated until the end of semester, many reported doubts that they would pass their course(s), especially in the last few weeks leading up the end of semester. Most of this group cited that distance learning did not suit either their approach to learning or their lifestyle at that point in time. For example, Deborah reported:

The fact is you try and do everything but you just can't fit it in so I think I might take the first half of next year to re-evaluate what I'm doing instead of just wasting more time.

\section{Discussion}

The study adopted a novel phenomenological video diary method to collect deep and meaningful stories from 20 students in their first-few weeks as a distance learner, and in 12 cases, through to completion of their first semester. Learner stories reveal many shades of grey to the "soft factors" of what it means to be a distance learner and provide a unique insight into the complexity of studying from a distance.

Results concur with Poskitt, Rees and Suddaby (2011) that the majority of distance learners are older than campus-based students and around half are likely to have responsibility for the care of dependent children. They are often professionals who are employed as many as $40+$ hours per 
week and are highly likely to be motivated by career-specific goals. However, the current study adds insight to highly affective, deeply emotional goals; the chance to have an education as an adult can be motivation itself.

From the outset of semester, stories revealed the extent to which first-time distance students and sometimes distance providers - have relatively little concept of what it is actually like to study by distance. Against this background, students do not always make realistic study choices in light of their personal circumstances. Students commonly perceive that distance study will not only be flexibly scheduled around commitments, but also "condensable" in to the hours they have available. As early as the orientation period, the perceived flexibility and self-paced nature of distance education appeared to create a false sense of security that seemed to invite some students to remain syllabus-bound, ignore non-essential tasks and - in the worst scenarios - to disengage and withdraw from courses. This finding reinforces the value of institutional support services that can help students calculate what is personally realistic during the path to enrolment. However, research findings caution institutions that while some students are open to being engaged by support services, others are not. A future challenge for distance providers is to not only design relevant services that can be made available at the point of need, but to dissuade learners from taking a "lone wolf" approach to distance study from the outset. Importantly, it is not enough to rely on chance that distance students will either take institution-led opportunities to engage in study-related interactions with others through new technologies or seek learning support from people in their immediate vicinity with whom they enjoy an established sense of relatedness.

The biggest challenge to overcome with the so-called "lone wolves" is to support them to appreciate that what is generally agreed to be true for students in physical learning environments - learners perform better and are more satisfied at institutions that cultivate positive working and social relations among different groups (Zhao \& Kuh, 2004) - is thought to be equally relevant in distance learning environments. The research findings indicate that technology now presents distance learners with the opportunity to interact with teachers and peers to an extent that rivals traditional campus-based teaching and learning. Notably, Poskitt, Rees and Suddaby (2011) report negligible differences between distance learners and campus-based learners in the frequency of their participation in active forms of learning such as contributing to discussions, asking questions, or working with others. To build a stronger sense of belonging or relatedness with students distributed at a distance, the research findings suggest that there is value in institutions supporting opportunities for first-time distance learners to engage in a variety of different online places and spaces for learning and knowledge generation. In this regard, Thornberg (1996) proposes four metaphors that resonate with the findings of the current study: Caves where distance learners can find time to reflect and come in to contact with themselves; Campfires are formal environments where students have the opportunity to listen to stories from which they construct knowledge from those with expertise and wisdom; Watering Holes are informal environments where students gather at a central source to discuss information and create meaning with their peers; and Mountain Tops, where students celebrate their findings and present their ideas to an audience. 
However, insights gained from learner stories reveal that few first-time distance students know how to be effective online learners. In concurrence with Jones Ramanau, Cross and Healing (2010), distance learners were seen to represent a "complex picture of minorities" some of whom are truly engaged in a wide range of digital activity at frequent intervals; while others rarely utilise the digital resources at their disposal. In concurrence with Poskitt, Rees and Suddaby (2011), the current research has also observed that mature-aged first-time distance learners are highly likely to rely on traditional email correspondence with their teachers. A future challenge for distance education providers is to develop student's academic capital and social confidence in the digital environment. The current study suggests that teachers are important role models whose interactions shape the digital culture and the sense of belonging among a community of online learners. In subtle contrast, Baxter (2012) has placed an emphasis on distance learners' peers as a primary source of inspiration; specifically those with the ability to "initiate and sustain very successful online interactions and relationships with other students" (p.122). However, the authors of the present study agree with Baxter (2012) that the engagement of distance learners is powerfully influenced by their ability to develop study-related relationships in a digital environment.

Finally, early interventions are important because the first six weeks are typically considered a high risk transition period for first-time learners (Krause Hartley, James \& McInnis, 2005). However, there is evidence from the video diaries that a second and significant "high-risk" period of disengagement exists for first-time distance learners towards the latter part of semester just before the final assignment was due. Although this second "at risk" period did not result in immediate withdrawal, it often meant that even highly motivated students began to question their ability to successfully complete their program of study. This feeling was particularly common among students who had indicated passive, surface study approaches and, in other words, had lost morale, procrastinated, and allowed their progress to stagnate following disappointment in earlier assignments. In contrast, the most resilient students during this second "high-risk" period were those who reflected on active, deep, and strategic approaches; particularly those who had established a support network to help them recover from any ebbs in morale. In support of this observation, Simonson, Schlosser and Orellana (2011) attribute success among distance learners to the qualities of abstract learning, intrinsic motivation, and possession of an internal locus of control. Arguably, the research findings suggest that students do not tend to "change their spots" in terms of their study orientation over the course of their first semester by distance. In other words, those who demonstrate passive, surface approaches from the outset are those most at risk during the second "high-risk" period that has been identified by this study. This finding raises questions about the optimum moments for institutions to intervene and support students in an effort to develop new habits of mind by evoking more active engagement.

\section{Conclusion}

The lack of available literature specific to the transition to distance learning - as distinct from campus-based learning-from a learner's perspective means an important gap exists in understanding the specific course design and learning support requirements for the particular circumstances of distance students. This study has in part helped to close this gap by revealing the 
many different "shades of grey" amongst distance learners, which in turn provides insight into the real life circumstances behind poor retention, progression, and completion among distance learners. Although the research suggests that some of the soft factors are beyond the control of distance providers, they should not be ignored when designing courses, explaining the nature of distance learning and developing targeted interventions and support services which go beyond a goulash approach. Distance providers and prospective students alike need to work together to design what is achievable in a way that is not just a crude calculation of hours available, predicated on the ill-informed assumption that distance learning is a "lone wolf" experience offering more flexibility than on-campus learning. Courses need to be designed to complement their busy lives and support services need to adequately help them survive beyond the first few weeks in an environment that is most likely starkly different from that of a campus learner.

\section{Acknowledgement}

Support for the original work was provided by the Australian Government Department of Industry, Innovation, Science, Research and Tertiary Education (DIISRTE) through the Dehub Project.

\section{References}

Adams, T., Banks, M., Davis, D., \& Dickson, J . (2010). The hobsons retention project: Context and factor analysis report. Retrieved from: http://www.aiec.idp.com/pdf/2010_AdamsBanksDaviesDickson_Wed_1100_BGallB_Paper. pdf

Allen, E., \& Seaman, J . (2013). Changing course: Ten years of tracking online education in the United States. Wellesley MA: Babson Survey Research Group and Quahog Research Group.

Anderson, B., Lee, S., Simpson, M., \& Stein, S. (2011). Study orchestrations in distance learning: Identifying dissonance and its implications for distance educators. International Review of Research in Open and Distance Learning, 12(5). Retrieved from http:// www.irrodl.org/ index.php/ irrodl/article/ view/ 977/ 1854

Australasian Survey of Student Engagement (AUSSE). (2010). Doing more for learning: Enhancing engagement and outcomes. Melbourne: Australian Council for Educational Research.

Baxter, J . (2012). Who am I and what keeps me going? Profiling the distance learning student in higher education. The International Review of Research In Open and Distance Learning, 13(4), 107-129.

Basit, T. N., \&Tomlinson, S. (eds) (2012). Social inclusion and higher education. Bristol: The Policy Press.

Braun, V., \& Clarke, V. (2003). Using thematic analysis in psychology. Qualitative Research in Psychology, 3, 77-101. 
Brown, M., Hughes, H., \&Delaney, L. (2015). Giving voice to distance learners: Methodological decisions and challenges. European J ournal of Open, Distance and E-learning, Best of EDEN RW8, 170-185.

Cashmore, A., Green, P., \& Scott, J . (2010). An ethnographic approach to studying the student experience: The student perspective through free form video diaries. The International J ournal of the First Year in Higher Education, 1(1), 106-111.

Daniel, J . (2011, J une 20th). 20 years of distance education in the garden of EDEN: Good news and bad news. Keynote presentation presented at the European Distance and eLearning Network Conference, Dublin.

Department of Employment, Education and Workplace Relations (DEEWR). (2010). Higher education statistics. All students. Canberra, Australia. Retrieved from https:// www.education.gov.au/higher-education-statistics

Higher Education Funding Council for England. (2009). Part-time first degree study: Entry and completion. Higher Education Funding Council for England. Retrieved from: http://www.hefce.ac.uk/pubs/year/ 2009/200918/

J ames, R., Krause, K-L., \&J ennings, C. (2009). The first-year experience in australian universities: Findings from 1994 to 2009. Melbourne University: Centre for the Study of Higher Education.

J elfs, A., \& Richardson, J . (2012). The use of digital technologies across the adult life span in distance education. British J ournal of Educational Technology (In press). Retrieved from: http:// onlinelibrary.wiley.com/journal/ 10.1111/(ISSN)1467-8535/ earlyview

J oint Information Steering Committee. (2007). In their own words: Exploring the learner's perspective on e-learning. Retrieved from: http:// www.jisc.ac.uk/intheirownwords

J ones, C., Ramanau, R., Cross, S., \& Healing, G. (2010). Net generation or digital natives: Is there a distinct new generation entering university? Computers and Education, 54(3), 722- 732.

Kift, S. (2009). Articulating a transition pedagogy to scaffold and to enhance the first year student learning experience in australian higher education: Final Report for ALTC fellowship programme. ALTC Resources.

Krause, K.-L., Hartley, R., J ames, R., \& McInnis, C. (2005). The first year experience in australian universities: Findings from a decade of national studies. Canberra: Australian Department of Education, Science and Training.

Ministry of Education. (2010). Provider-based enrolments. Education Counts. Received from: http://www.educationcounts.govt.nz/statistics/tertiary_education/participation 
Nunan, T. (2005). Markets, distance education, and australian higher education. The International Review of Research In Open and Distance Learning, 6, (1). Retrieved from http:// www.irrodl.org/index.php/irrodl/article/ view/ 223/306

Online Learning Task Force. (2011). Collaborate to compete: Seizing the opportunity of online learning for UK higher education. Report to HEFCE by the Online Learning Taskforce, January 2011.

Pittaway, S., \&Moss, T. (2006). Contextualising student engagement: Orientation and beyond in teacher education. Paper presented at the 9th Pacific Rim First Year in Higher Education Conference: Engaging Students. Griffith University, Australia.

Poskitt, J ., Rees, M., Suddaby, G. (2011). Engaging with university at a distance: The differences in levels of student engagement among extramural and campus-based students. In A. Radolf (Ed.), Student engagement in New Zealand's universities (pp.70-76). Melbourne : Australian Council for Educational Research (ACER).

Reeves, T. C. (2006). Design research from the technology perspective. In J . V. Akker, K. Gravemeijer, S. McKenney, \&N. Nieveen (Eds.), Educational design research (pp. 86-109). London: Routledge.

Riddle, M., \&Arnold, M. (2007). The day experience method: A resource kit. Retrieved from: http:// www.matthewriddle.com

Simonson, M., Schlosser, C., \& Orellana, A. (2011). Distance education research: A review of the literature. J ournal of Computing in Higher Education, 23, 124-142.

Simpson, O. (2003). Student retention in online, open and distance learning. Kogan Page, London and Stirling Va.

Simpson. O. (2009). Motivating learners in an open and distance learning: Do we need a new theory of learner support? Open Learning: The J ournal of Open and Distance Learning, 23(2), 159-170.

Tennant, M., McMullen, C., \& Kaczynski, D. (2009) 'Learning in the digital age', in Teaching, learning and research in higher education. Hoboken: Routledge.

The Australian. (2011, September 21st). Australian undergraduate attrition rates. Retrieved from: http:// www.theaustralian.com.au/higher-education/ university-rankings/attrition$\underline{\text { rates/story-fna15id1- } 1226141560486}$

Thornberg, D. (1996). Campfires in cyberspace: Primordial metaphors for learning in the 21st century. Available from http://itdl.org/journal/ oct_04/invited01.htm 
Tyler-Smith, K. (2006). Early attrition among first-time elearners: A review of factors that contribute to drop-out, withdrawal and non-completion rates of adult learners undertaking elearning programmes. J ournal of Online Learning and Teaching, 2(2).

Zawacki-Richter, O. (2009). Research areas in distance education: A delphi study. International Review of Research in Open and Distance Learning, 10(3), 1-17.

Zepke, N., \& Leach, L. (2010). Beyond hard outcomes: 'Soft' outcomes and engagement as student success. Teaching in Higher Education, 15(6), pp. 661-673.

Zhao, C., \&G. Kuh. 2004. Adding value: Learning communities and student engagement. Research in Higher Education, 45, 115- 38.

(c) Brown, Hughes, Keppell, Hard and Smith

\section{Athabasca University}



